Linha D’Água (Online), São Paulo, v. 33, n. 2, p. 161-188, maio-ago. 2020

\title{
O ENSINO DA APRESENTAÇÃO ORAL EM FRANCÊS E SUA CONTRIBUIÇÃO PARA O LETRAMENTO ACADÊMICO E PARA O PLURILINGUISMO NA CIÊNCIA
}

\section{THE TEACHING OF ORAL PRESENTATION IN FRENCH AND ITS CONTRIBUTION TO ACADEMIC LITERACY AND TO THE MULTILINGUALISM IN SCIENCE}

\author{
Eliane Gouvêa Lousada* \\ Universidade de São Paulo, São Paulo, SP, Brasil \\ Emily Caroline da Silva** \\ Universidade de São Paulo, São Paulo, SP, Brasil \\ Ana Paula Silva Dias **** \\ Universidade de São Paulo, São Paulo, SP, Brasil
}

\begin{abstract}
Resumo: No contexto da internacionalização das pesquisas nas universidades, este artigo apresenta parte dos resultados de um curso sobre 0 ensino de gêneros textuais da esfera acadêmica em francês. Com base nos pressupostos teóricos do Interacionismo Sociodiscursivo, nos aportes sobre o Letramento Acadêmico e em consideraç̃eses sobre o plurilinguismo na ciência, 0 estudo analisou 0 material didático proposto e as apresentações orais dos alunos através de uma abordagem comparativa entre produção intermediária e produção final. Os resultados revelam um desenvolvimento das capacidades de linguagem dos estudantes e uma consequente contribuição para o Letramento Acadêmico em francês, visando a construir uma ciência plurilíngue.
\end{abstract}

Palavras-chave: letramento acadêmico; gêneros textuais; plurilinguismo; produção oral; língua estrangeira.

Abstract: In the context of research internationalization at universities, this article presents part of the results of a course upon the teaching of textual genres of the academic sphere in the French language. Based on the theoretical framework of the Sociodiscursive Interactionism, on the contributions of the Academic Literacy and on the discussions about multilingualism in science, the study

\footnotetext{
* Professora doutora da FFLCH, Universidade de São Paulo - USP, São Paulo, SP, Brasil. Bolsista Produtividade CNPq; https://orcid.org/0000-0002-3065-2769; elousada@usp.br ** Doutoranda da FFLCH, Universidade de São Paulo - USP, São Paulo, SP, Brasil; https://orcid.org/0000-0003-0798-4607; emilycsilva@usp.br *** Mestra pela FFLCH, Universidade de São Paulo - USP, São Paulo, SP, Brasil; https://orcid.org/0000-0002-8570-567X; ana9.pauladias@gmail.com
}

http://dx.doi.org/10.11606/issn.2236-4242.v33i2p161-188 
Linha D’Água (Online), São Paulo, v. 33, n. 2, p. 161-188, maio-ago. 2020

analyzes the didactic material and the student's oral presentations using a comparative approach between the intermediate and the final productions. The results reported a development of students' language abilities and a consequent contribution to the Academic Literacy in the French Language, in order to build a multilingual science.

Keywords: Academic Literacy; Textual Genres; Multilingualism; Oral Production; Foreign Languages.

\section{Introdução}

A internacionalização tem ganhado grande destaque nas universidades nas últimas duas décadas, tornando-se fator chave não somente para os rankings de qualidade das universidades, mas também para avaliação dos programas, cursos, pesquisas e, portanto, para a atribuição de bolsas e recursos. No Brasil, por exemplo, os programas de pós-graduação passam por uma avaliação quadrienal pela Coordenação de Aperfeiçoamento de Pessoal de Ensino Superior (CAPES) em que a internacionalização aparece como um dos critérios de avaliação da qualidade do programa.

Esse movimento não é apenas nacional: em universidades estrangeiras, a internacionalização tem sido bastante valorizada pelo número de alunos estrangeiros acolhidos, pela presença de pesquisadores estrangeiros em congressos internacionais (não apenas como convidados), pelos projetos de pesquisa em rede, dos quais fazem parte professores de universidades de diferentes países, e pelas publicações que reúnem pesquisadores de variadas nacionalidades.

Buscando compreender como a dimensão internacional se tornou parte integral da educação de nível superior e da pesquisa científica no Brasil, Ramos (2018) realizou um estudo com mais de trezentos coordenadores de programas de pós-graduação brasileiros bem avaliados pela CAPES, isto é, com notas 6 e 7 . A pesquisa identificou que os programas de excelência destacam uma concepção de internacionalização orientada para algumas atividades. Dentre elas, a mobilidade acadêmica para o exterior foi vista como o principal mecanismo de acesso à experiência internacional, à formação de redes e ao estabelecimento de colaborações internacionais em pesquisa. Além disso, a pesquisa apontou que a presença de docentes formados no exterior, capazes de mobilizar suas redes externas para formar parcerias científicas, é colocada como condição chave para a internacionalização da pós-graduação e da pesquisa no Brasil.

LOUSADA, E. G., SILVA, E. C., DIAS, A. P. S. 0 ensino da apresentação oral em francês e sua contribuiç̃ó para o Letramento Acadêmico e para o Plurilinguismo na ciência 
Nesse sentido, a existência de bolsas nacionais e internacionais de fomento à mobilidade (como o Programa de Doutorado Sanduíche no Exterior, da CAPES, dentre outras) tem proporcionado aos estudantes de todas as áreas do conhecimento inúmeras oportunidades de uma qualificação no exterior, nos mais diversos países, tanto enviando quanto atraindo estudantes e pesquisadores. $\mathrm{Na}$ área de humanidades, a língua francesa tem papel de destaque na internacionalização das pesquisas produzidas, uma vez que muitos alunos optam por fazer estágio doutoral em universidades francófonas e vários são os trabalhos de pesquisadores e pós-graduandos que utilizam a língua francesa para divulgar os estudos oralmente ou por escrito (SILVA, LOUSADA, 2014; LOUSADA, ROCHA, GUIMARÃES-SANTOS, 2015).

Também em contexto brasileiro, mas especificamente na Universidade de São Paulo (USP), pesquisas anteriores (SILVA, MENEZES, LOUSADA, 2016) examinaram o estado das políticas linguísticas voltadas à pluralidade linguística e cultural e constataram, através de análise documental, políticas explícitas nesse sentido no curso de Letras, no ingresso da graduação e pós-graduação e nos processos seletivos para mobilidade acadêmica internacional. No momento atual, poderíamos incluir, no âmbito das políticas linguísticas no nível da pós-graduação da USP, os programas voltados à internacionalização que têm sido desenvolvidos pela Pró-Reitoria de Pós-Graduação, como, por exemplo o CAPES-PRINT. Além disso, destacamos o trabalho do Laboratório de Letramento Acadêmico ${ }^{1}$ com sede na FFLCH (Faculdade de Filosofia, Letras e Ciências Humanas) e um curso sobre Produção Textual, em inglês e em francês, que é objeto deste artigo, além de outras iniciativas.

Para atender à demanda de formação no contexto de internacionalização das pesquisas na área de humanidades, um curso sobre Produção Textual Acadêmica em Francês foi proposto em parceria com a Pró-Reitoria de Pós-Graduação e o Laboratório de Letramento Acadêmico (LLAC), visando preparar e qualificar os estudantes universitários para situações acadêmicas de produção de textos orais e escritos, como escrita de resumos, apresentações orais, etc. Dentre as principais ações do Laboratório, encontram-se as tutorias de escrita acadêmica e formação

http://letramentoacademico.fflch.usp.br/

LOUSADA, E. G., SILVA, E. C., DIAS, A. P. S. 0 ensino da apresentaçã̃o oral em francês e sua contribuiç̃̃o para o Letramento Acadêmico e para o Plurilinguismo na ciência 
de tutores; palestras e oficinas; consultorias; cursos de extensão, cursos associados à Pró-Reitoria de Pós-Graduação e constituição de um espaço de pesquisa e reflexão sobre o letramento (FERREIRA, LOUSADA, 2016).

Este artigo visa, assim, apresentar um recorte dos resultados de uma das edições do curso sobre Produção Textual Acadêmica em francês, focalizando o trabalho com o ensino do gênero apresentação oral. Mais especificamente, objetiva-se apresentar (a) o material didático proposto e (b) uma síntese dos resultados da análise das produções textuais dos alunos. Para isso, este artigo organiza-se em três seções, além desta Introdução e das Considerações Finais. A seção 1 apresenta o referencial teórico, abordando quatro tópicos: o Plurilinguismo na ciência, o papel da linguagem no desenvolvimento humano, um quadro teórico-metodológico para pensar e ensinar gêneros textuais e, finalmente, os estudos sobre o Letramento Acadêmico. A seção 2 explora os procedimentos metodológicos, apresentando o contexto de realização do curso, a metodologia de elaboração do material didático e as categorias de análise para as produções textuais dos alunos. A seção 3 reúne os resultados das análises sobre o material didático e sobre as produções textuais dos alunos. Finalmente, as considerações finais discutem as limitações encontradas e as contribuições do presente estudo.

\section{Referencial teórico}

Nesta seção, discutiremos inicialmente a questão do plurilinguismo na ciência, ressaltando sua importância no mundo globalizado de hoje; em seguida, apresentaremos as bases de nosso quadro teórico, fundamentado no Interacionismo Social e, também, no Interacionismo Sociodiscursivo; dando continuidade, traremos as noções desse quadro teórico voltadas para a Didática das Línguas e, finalmente, discutiremos algumas questões relativas ao Letramento Acadêmico.

\section{a) Plurilinguismo na ciência}

A relação entre as línguas e a ciência tem sido interrogada por diversos pesquisadores (para citar alguns, GAJO, 2013; CERQUIGLINI, 2013; BLANCHET, 
Linha D'Água (Online), São Paulo, v. 33, n. 2, p. 161-188, maio-ago. 2020

CHARDENET, 2016; BLANCHET, 2017). Longe de visualizarem a pluralidade linguística como um entrave entre comunidades científicas, eles apresentam uma postura favorável ao plurilinguismo na produção, circulação e transmissão dos saberes na ciência (CERQUIGLINI, 2013).

Ao analisar o lugar que as línguas ocupam na elaboração e transmissão dos saberes na produção científica, Gajo (2013) aponta para a necessidade de se repensar os termos de elaboração e transmissão, destacando três funções primordiais da linguagem nesse contexto. A primeira delas é a mediação (já descrita por Vygotski e à qual retornaremos mais a frente): a língua realiza a mediação entre o pensamento e linguagem, entre os saberes e a colocação desses saberes em discurso. Essa função de mediação se dá, por exemplo, na formulação dos saberes através de hipóteses, teoremas, definições, etc. A segunda delas é a de remediação, que se produz quando o discurso é reformulado, reinterrogado ou ajustado em função das ferramentas linguísticas mobilizadas. Quando tal reformulação se faz em língua estrangeira para uma outra comunidade científica, por exemplo, o autor a chama de re-mediação (com hífen). Nesse caso, a língua estrangeira permite ao produtor não somente ajustar o discurso em função dos meios linguísticos da outra língua, mas lhe permite também um olhar alternativo sobre as relações entre a linguagem e o saber. Segundo Gajo, "é nesse duplo nível que o plurilinguismo pode servir ao mesmo tempo de lupa e de recurso suplementar no processo de construção de saberes" (GAJO, 2013, p. 99). Nesse sentido, mesmo um produto científico de aparência monolíngue (como um artigo, por exemplo), pode ter se beneficiado de um trabalho amplamente plurilíngue, o qual não será necessariamente visível. Finalmente, a terceira função é a indexicalidade, isso é, a ancoragem que o discurso tem em seu contexto de produção, uma vez que é sempre portador de uma voz incluindo a de uma corrente teórica ou a de uma comunidade científica. Portanto, os discursos científicos não são neutros e podem dar margem a monopólios científicos e hegemonias geopolíticas (BLANCHET, 2017). Com base nesses pontos, evidencia-se a relevância do plurilinguismo ${ }^{2}$ na ciência e a necessidade de políticas linguísticas explícitas na academia.

2 Na Europa, o Observatório do Plurilinguismo reúne dados e publicações sobre o desenvolvimento de iniciativas e políticas linguísticas (https://www.observatoireplurilinguisme.eu//).

LOUSADA, E. G., SILVA, E. C., DIAS, A. P. S. 0 ensino da apresentação oral em francês e sua contribuição para o Letramento Acadêmico e para o Plurilinguismo na ciência 
Linha D’Água (Online), São Paulo, v. 33, n. 2, p. 161-188, maio-ago. 2020

Essas ponderações são pertinentes para discutir o curso cujos dados apresentamos neste artigo, pois permitem compreender o papel das línguas na produção de saberes científicos por pós-graduandos brasileiros que estarão em mobilidade acadêmica no exterior. Além disso, elas permitem problematizar a questão das línguas na divulgação da ciência, refutando a hegemonia linguística e apoiando a pluralidade linguística também na esfera científica.

\section{b) O papel da linguagem no desenvolvimento humano}

Este estudo fundamenta-se no paradigma do interacionismo social (BRONCKART, 2017), assumindo primordialmente a ideia de que a linguagem é o fator crucial que distingue o desenvolvimento humano, transformando-o radicalmente. Interagindo com o meio em que vive, o homem é capaz de se apropriar de conhecimentos nunca antes experimentados apenas pelo relato de seus pares, o que indica o caráter sócio-histórico do desenvolvimento humano (VYGOTSKI, 1934/1997). Essa concepção de desenvolvimento humano se constitui como movimento não linear, repleto de altos e baixos e impulsionado pela interação social.

A importância que a linguagem assume nesse quadro se dá justamente porque ela medeia a relação entre o homem e o meio: o homem se apropria da linguagem, a interioriza e ela passa a funcionar como instrumento para autorregulação dos próprios pensamentos e comportamentos (VYGOTSKI, 1934/1997). Assim, “a linguagem não expressa, não reflete, não significa o pensamento. Ela funciona como um meio [médium], ela faz com que o processo de pensamento se realize; em suma, o pensamento se faz através dela” (FRIEDRICH, 2012, p. 94). Nessa perspectiva, pensamento e linguagem não são espelhos um do outro, mas funcionam em constante interação. Em síntese, o papel da linguagem se constitui como instrumento simbólico que medeia a relação entre o sujeito e o meio em que vive e também a relação do sujeito consigo mesmo, pelo pensamento.

A linguagem se materializa em textos, orais ou escritos, produzidos sempre a partir de atividades de linguagem que ocorrem socialmente em função dos objetivos e/ou interesses dos produtores e tendo em vista locais, destinatários e momentos específicos (BRONCKART, 1999, p. 72). Pelo fato de os textos apresentarem 
Linha D'Água (Online), São Paulo, v. 33, n. 2, p. 161-188, maio-ago. 2020

características relativamente estáveis de parâmetros sociossubjetivos e textuais, pode-se dizer que eles formam "famílias" ou "espécies" de textos (BRONCKART, 1999 , p. 72). Sendo assim, justifica-se que sejam chamados de "gêneros de texto" ou gêneros textuais (BRONCKART, 1999, p. 137).

\section{c) Um quadro teórico-metodológico para pensar e ensinar gêneros textuais}

Com o intuito de contribuir para o campo da Didática das Línguas, pesquisadores do Interacionismo Sociodiscursivo (ISD), sobretudo Bronckart (1999, 2006), propuseram um modelo de análise textual baseado na arquitetura interna dos textos. Esse modelo considera primeiramente a situação de ação da linguagem através da análise do contexto de produção do texto: analisa-se o contexto físico (emissor, receptor, lugar e o momento de produção), bem como o contexto sociossubjetivo (enunciador, destinatário, local social dos interlocutores, objetivo da interação) e o gênero de texto produzido. Em seguida, passa-se às camadas do folhado textual, estruturadas em três níveis superpostos:

- a infraestrutura textual: plano geral dos conteúdos temáticos; tipos de discurso (narração, relato, discurso teórico e discurso interativo); e sequências textuais (narrativas, explicativas, argumentativas, injuntivas, descritivas e dialogais);

- os mecanismos de textualização: conexão (organizadores textuais de nível micro ou macro); e coesão nominal (séries coesivas nominais e cadeias anafóricas).

- os mecanismos de responsabilização enunciativa: posicionamento construído por meio da inserção de vozes (voz do autor empírico, vozes sociais e vozes dos personagens) e das modalizações (lógicas, deônticas, apreciativas e pragmáticas).

Sempre com foco na Didática das Línguas e nas contribuições para a renovação do ensino da produção textual (BRONCKART, 2010), os pesquisadores 
da Universidade de Genebra utilizaram esse modelo de análise, para estruturar o ensino e a aprendizagem da produção textual (SCHNEUWLY, DOLZ, 2004). De um lado, os gêneros textuais se constituem como uma forma de aprendizagem social, permitindo que o aprendiz aja socialmente. De outro, eles funcionam como megainstrumento para o desenvolvimento de capacidades de linguagem, posteriormente transferíveis à produção de outros gêneros. Além disso, os tipos de discurso (BRONCKART, 1999) funcionam como formatos que contribuem para o desenvolvimento de formas de raciocínio. Bronckart (2006, p. 155) indica que se por um lado, os gêneros são importantes para a aprendizagem social, por outro, os tipos de discurso são importantes para o desenvolvimento do raciocínio lógico e semilógico (no discurso teórico), causais/cronológicos (nos relatos e narrações) e práticos (nas interações dialogais).

Para os pesquisadores genebrinos, três conceitos são fundamentais para se pensar o ensino através dos gêneros textuais. $O$ primeiro deles, o conceito de capacidades de linguagem (DOLZ, PASQUIER, BRONCKART, 1993, p. 30), diz respeito às aptidões requeridas para a produção de um texto em uma dada situação de interação e se divide em:

- capacidades de ação, as quais são mobilizadas na adaptação da produção linguageira as características do contexto, destinatário e referente;

- capacidades discursivas, que mobilizam modelos discursivos pertinentes para uma determinada ação linguageira;

- capacidades linguístico-discursivas, que se referem ao domínio das inúmeras operações psicolinguísticas necessárias para a produção textual.

A fim de se trabalhar as capacidades de linguagem dos alunos na produção de gêneros textuais, um segundo conceito se mostra essencial: o de modelo didático (MD) do gênero textual, que se define como "um objeto descritivo e operacional, construído para apreender o fenômeno complexo da aprendizagem de um gênero e, assim, orientar suas práticas" (DE PIETRO, 
ERARD, KANEMAN-POUGATCH, 1996/1997, p. 108, tradução nossa) $)^{3}$. Segundo De Pietro e Schneuwly (2003), o modelo didático possui uma certa estrutura, ele evidencia as dimensões ensináveis e se constitui como objeto de uma construção tanto a partir da literatura - linguística e didática - sobre aquele gênero, quanto a partir das práticas sociais de referência e das práticas linguageiras dos alunos. O MD opera como instrumento para posterior elaboração de sequências didáticas. Sendo assim, ele não é um objeto teoricamente puro, mas um modelo pensado em função do ensino de determinado gênero textual. A imagem abaixo ilustra seu funcionamento.

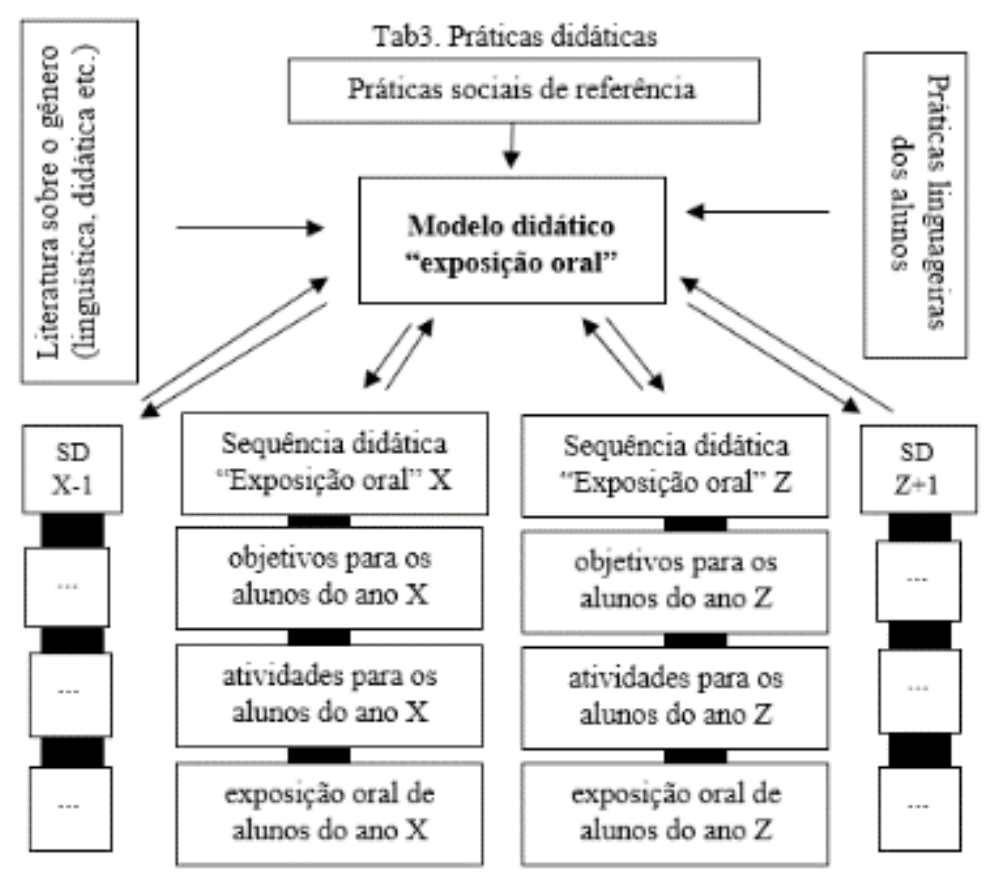

Quadro 1: Esquema do modelo didático Fonte: De Pietro, Schneuwly (2003), tradução nossa

Uma vez construído o modelo didático, é possível elaborar sequências didáticas (DOLZ, NOVERRAZ, SCHNEUWLY, 2004) para o ensino do gênero.

3 No original: "Un modèle est un objet descriptif et opérationnel (l'équilibre n'est pas facile à trouver entre ces pôles) construit pour appréhender le phénomène complexe de l'apprentissage d'un genre et ainsi orienter les pratiques." (DE PIETRO, ERARD, KANEMAN-POUGATCH, 1996/1997, p. 108).

LOUSADA, E. G., SILVA, E. C., DIAS, A. P. S. 0 ensino da apresentação oral em francês e sua contribuição para o Letramento Acadêmico e para o Plurilinguismo na ciência 
A sequência didática é definida pelos autores como um "conjunto de atividades escolares organizadas, de maneira sistemática, em torno de um gênero textual oral ou escrito", com o objetivo de "dar acesso aos alunos a práticas de linguagem novas ou dificilmente domináveis" (DOLZ; NOVERRAZ; SCHNEUWLY, 2004, p. 97-98). Através das atividades nela contidas, os aprendizes poderão mobilizar, desenvolver e ampliar suas capacidades de linguagem, passando a agir nas situações de comunicação de forma mais consciente.

A sequência didática se estrutura em quatro etapas clássicas, chamadas de módulos: a apresentação da situação, a produção inicial, os módulos e a produção final, podendo estender os módulos e incluir produções intermediárias (conforme Quadro 2). Justamente por possuir produções iniciais, intermediárias e final, ela permite que se verifique o desenvolvimento das capacidades de linguagem dos aprendizes e que o professor adapte os módulos em função das necessidades da turma.

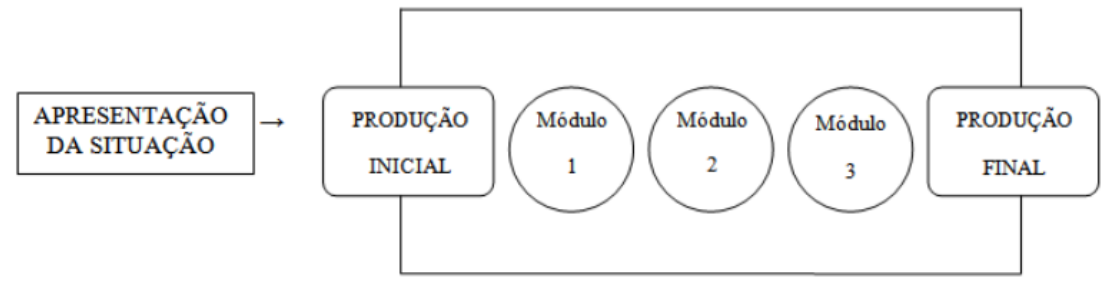

Quadro 2: Esquema do modelo didático

Fonte: Dolz, Noverraz, Schneuwly, 2004, p. 98

\section{d) O letramento acadêmico}

A produção de gêneros textuais na esfera acadêmica, no entanto, possui características peculiares. No contexto universitário, com frequência, os estudantes não se encontram preparados para produzir os gêneros demandados na graduação, tais como resumo, resenha, ensaio, apresentação oral, etc. Portanto, encontra-se um primeiro desafio: o de um uso da linguagem mais formal, da esfera dos estudos universitários (BAZERMAN, BONINI, FIGUEIREDO, 2009; DELCAMBRE; LAHANIER-REUTER, 2010; LOUSADA, DEZUTTER, 2016; LOUSADA, DEZUTTER, ZAVAGLIA, 2017). 
Quando esses estudantes ingressam na pós-graduação (mestrado e doutorado), é exigido que eles aprendam também os gêneros da esfera científica/acadêmica, tais como artigo, resumo para congresso, relatório de pesquisa, apresentação oral ("comunicação") etc., o que constitui um segundo desafio (LOUSADA, DEZUTTER, 2016). No contexto da internacionalização, o desafio torna-se triplo: demanda-se que esses estudantes produzam gêneros da esfera científica/acadêmica, porém em língua estrangeira. Assim, evidencia-se cada vez mais a necessidade da ampliação de centros de escrita acadêmica, a exemplo do que já existe em países anglófonos (LOUSADA; GUIMARÃES-SANTOS, 2018), ou laboratórios de letramento acadêmico que ofereçam suporte, cursos e formações não apenas em língua materna, mas, também, em línguas estrangeiras.

Nesse contexto, desponta outro desafio: não apenas escrever sobre a pesquisa em língua estrangeira, o que gera muito frequentemente apreensão e preocupação por parte de professores e pós-graduandos, mas, também, apresentá-la, falar sobre ela. Embora, por um lado, a escrita acadêmica seja extremamente exigente e demande muito tempo de aprendizagem, no oral, a situação de exposição simultânea, em que o público e o apresentador compartilham o mesmo espaço-tempo da apresentação, é fonte de muito estresse. Por isso, optamos por realizar um estudo sobre a aprendizagem do oral formal para a apresentação de pesquisas em francês como língua estrangeira.

Se retomarmos o ensino do oral formal em ambiente escolar, não necessariamente em contexto acadêmico, podemos dizer que esse só passou a ser trabalhado em escolas francesas a partir da renovação do ensino do francês nos anos 60. Nesse momento, por influência da linguística estrutural, o ensino da língua oral tornase tão importante quanto o ensino da língua escrita (DOLZ; SCHNEUWLY, 2009). Como afirmam Dolz e Schneuwly, com a renovação do ensino:

Os novos programas e metodologias abandonam as orientações como, por exemplo, “aprender a exprimir corretamente suas ideias”, que traduzem a concepção tradicional da língua como ferramenta de representação do pensamento e colocam 
em evidência a importância de aprender a se exprimir em verdadeiras situações de comunicação. (DOLZ; SCHNEUWLY, 2009, p. 14, tradução nossa) ${ }^{4}$.

Com o foco na aprendizagem de como se expressar em diferentes situações de comunicação, surge a questão do ensino da produção de gêneros textuais. Como apontam Dolz, Noverraz e Schneuwly (2004), os textos que produzimos possuem características diferentes e são justamente essas características que permitem classificá-los como pertencentes a um determinado gênero e não a outro. Isso ocorre porque tais textos, orais ou escritos, foram produzidos em diferentes situações de comunicação, ou seja, elaboramos de maneira diferente uma apresentação oral sobre nossa pesquisa para um congresso e uma explicação informal sobre o mesmo tema em um grupo de pesquisa, por exemplo. Os autores sustentam, portanto, que é possível ensinar a produzir textos orais ou escritos através de sequências didáticas, que têm "a finalidade de ajudar o aluno a dominar melhor um gênero de texto, permitindo-lhe, assim, escrever ou falar de uma maneira mais adequada numa dada situação de comunicação" (DOLZ; NOVERRAZ; SCHNEUWLY, 2004, p. 97).

Nas pesquisas com base no ISD, a questão da aprendizagem do oral formal não é nova, apesar de ter sido menos explorada que a produção de textos escritos. Da mesma forma, no âmbito dos estudos sobre o letramento acadêmico, enfatiza-se muito mais a necessidade de produzir textos escritos que são exigidos no contexto acadêmico. No entanto, textos orais também fazem parte desse contexto e devem, portanto, ser trabalhados e ensinados.

Cientes desses desafios, no Grupo ALTER-AGE-CNPq, temos realizado pesquisas, que procuram, além de propor estudos e reflexões sobre a questão, fornecer ferramentas práticas para auxiliar os alunos na produção de gêneros acadêmicos. Nessa perspectiva, propusemos, com o apoio do projeto CAPES-DFATD (2017-2019), um site ${ }^{5}$ de auxílio para a produção de gêneros acadêmicos, para que

\footnotetext{
4 «Les nouveaux programmes et méthodologies abandonnent les formules telles que 'apprendre à exprimer correctement ses idées' qui traduisent la conception traditionnelle de la langue comme outil de représentation de la pensée et mettant en avant l'importance d'apprendre à s'exprimer dans de véritables situations de communication » (Dolz; Schneuwly, 2009, p. 14).

5 http://literac.fflch.usp.br
}

LOUSADA, E. G., SILVA, E. C., DIAS, A. P. S. 0 ensino da apresentação oral em francês e sua contribuição para o Letramento Acadêmico e para o Plurilinguismo na ciência 
Linha D’Água (Online), São Paulo, v. 33, n. 2, p. 161-188, maio-ago. 2020

os alunos possam se formar para o letramento acadêmico de forma autônoma. Como parte das reflexões propiciadas por nossas pesquisas, propusemos o curso de "Produção Textual Acadêmica", cujos dados analisamos neste artigo e que apresentamos a seguir.

\section{Contexto de estudo e procedimentos metodológicos}

Para apresentar os procedimentos metodológicos, esta seção se organiza em apresentação do contexto de realização do curso, descrição do modelo didático, identificando as características ensináveis do gênero, e relato das etapas de trabalho com o gênero no curso.

\section{a) Contexto de realização do curso}

O curso cujos dados foram analisados foi promovido em parceria com o $\mathrm{La}^{-}$ boratório de Letramento Acadêmico da FFLCH-USP e com a Pró-Reitoria de Pós-Graduação da Universidade de São Paulo. Seu público-alvo são doutorandos que almejam ou se preparam para participar de programas de intercâmbio, como o Programa de Doutorado Sanduíche no Exterior - financiado pela CAPES -, ou mestrandos e doutorandos que vão apresentar suas pesquisas no exterior, em congressos e seminários acadêmicos/científicos. A carga horária total do curso foi composta de vinte e uma horas presenciais e nove horas de tutorias, isso é, sessões individualizadas, em que os estudantes eram atendidos por tutores do curso, de maneira a ter uma assistência mais direcionada, além de comentários e retornos de como aprimorar suas produções textuais orais ou escritas. Para ingresso no curso, é necessário, em princípio, que os alunos tenham um nível linguístico a partir do B2 do Quadro Comum Europeu de Referência. No entanto, além de os alunos terem um nível linguístico bastante heterogêneo, mesmo com essa exigência, pois alguns têm nível $\mathrm{B} 2$, outros $\mathrm{C} 1$, muitas vezes são aceitos alunos de nível $\mathrm{B} 1$, pois esses têm compromisso acadêmico já previsto que necessita do uso do francês em 
contexto francófono, e a proposta do curso é atender esses alunos 6 . O curso contou com três edições, sendo a primeira delas em julho de 2019, a segunda, no primeiro semestre de 2019 e a terceira, no segundo semestre de 2019.

A edição analisada no presente estudo foi a primeira (julho de $2019^{7}$ ), a qual obteve oito alunos inscritos. Com relação ao conteúdo, o curso se dividiu em sete módulos que abordaram os gêneros textuais da esfera acadêmica/científica: resumo (abstract e para congresso), apresentação oral, artigo científico. Também foram trabalhados os chamados gêneros ocultos (SWALES, 1996), tais como: email para o orientador, apresentação de si e da pesquisa para os colegas; conversa com o orientador. Além disso, o curso incluiu um trabalho com aspectos transversais, como o ato de resumir, os mecanismos de inserção de vozes dos autores, a expressão da oposição de ideias, etc. Para o gênero apresentação oral, foram destinados três módulos: 4,5 e 7 .

\section{b) O modelo didático do gênero apresentação oral}

Conforme o esquema de De Pietro e Schneuwly (2003), anteriormente citado no Quadro 1, para elaborar o modelo didático (MD), baseamo-nos (i) nas práticas sociais de referência e (ii) nas práticas linguageiras dos alunos, analisando exemplares autênticos desse gênero produzidos em língua francesa - registrados em filmagens -, tanto produzidos em contexto francófono ${ }^{8}$ quanto em contextos lusófonos ${ }^{9}$. Além disso, fundamentamo-nos (iii) nos conhecimentos já produzidos pelos experts que estudaram gêneros textuais similares, como a exposição oral em

6 Observamos, nas três edições do curso, que, contrariamente ao caso do mesmo curso em inglês, é difícil encontrar alunos com nível avançado de francês. $E$, apesar disso, esses alunos têm bolsas e compromissos com a pesquisa em países francófonos, o que nos leva a aceitar diferentes níveis linguísticos, desde que haja necessidade comprovada da parte dos alunos.

7 Nesta edição, o curso foi ministrado pelas Profas. Eliane Gouvêa Lousada, Jaci Brasil Tonelli e Ana Paula Silva Dias.

8 Para a análise das apresentações orais em francês, baseamo-nos em apresentações filmadas por nós em congressos francófonos ou coletadas em sites da internet (por exemplo, o concurso "Minha tese em 180 segundos".

9 Esses dados foram extraídos da tese de Zani (2018).

LOUSADA, E. G., SILVA, E. C., DIAS, A. P. S. 0 ensino da apresentação oral em francês e sua contribuição para o Letramento Acadêmico e para o Plurilinguismo na ciência 
Linha D’Água (Online), São Paulo, v. 33, n. 2, p. 161-188, maio-ago. 2020

contexto escolar (DOLZ, NOVERRAZ, SCHNEUWLY, 2004) ou a comunicação oral em evento científico (ZANI, 2018).

A apresentação oral - também conhecida, nos congressos, como comunicação oral - é um dos gêneros textuais que pertence à esfera acadêmica, sendo uma ferramenta para o estudante-pesquisador ou pesquisador divulgar, em um determinado tempo (usualmente entre 15 a 30 minutos a depender do contexto), sua pesquisa em curso ou concluída, permitindo, posteriormente, que os dados apresentados sejam discutidos (ZANI, 2018; BUENO, ZANI, 2019). Esse gênero é muito comum em eventos científicos (congressos, seminários, encontros), mas também é utilizado em cursos, como instrumento para apresentar, socializar e discutir os resultados ou o andamento de um trabalho de pesquisa. Pode-se dizer que o gênero se enquadra no que Dolz, Noverraz e Schneuwly (2004) definem como "exposição oral”, isto é “[...] um gênero textual público, relativamente formal e específico, no qual um expositor especialista dirige-se a um auditório, de maneira (explicitamente) estruturada, para lhe transmitir informações, descrever-lhe ou the explicar alguma coisa." (DOLZ, NOVERRAZ, SCHNEUWLY, 2004, p. 218).

Os conteúdos temáticos de uma apresentação oral normalmente compreendem: a) uma introdução que parta de uma problemática encontrada na realidade, de uma carência em determinada área de pesquisa, ou de uma continuidade a partir de pesquisas anteriores - problemática essa que levará à questão norteadora e ao objetivo do trabalho ou da pesquisa. É justamente uma boa apresentação da problemática que convencerá a audiência da relevância e da pertinência daquele estudo. Nessa introdução, são explicitados os objetivos gerais da pesquisa e o objetivo daquela apresentação específica; b) breve apresentação do quadro teórico e dos procedimentos metodológicos do estudo; c) descrição dos principais resultados obtidos no estudo, mesmo que intermediários, e interpretação dos mesmos à luz do quadro teórico, retomando os objetivos do estudo; d) contribuição da pesquisa, destacando possíveis continuações para o estudo a partir das prováveis lacunas que não tenham sido preenchidas, terminando com as considerações finais que dialoguem com a problemática inicial.

No que tange à planificação do texto, tais conteúdos são organizados pelo produtor do texto nas seguintes fases: abertura (com saudação ao público e breve 
apresentação pessoal, legitimando sua fala), introdução ao tema, apresentação do plano da exposição, desenvolvimento e encadeamento dos diferentes temas e subtemas, conclusão e encerramento. Com relação aos tipos de discurso (BRONCKART, 1999) predominantes, destacam-se o discurso interativo (mundo discursivo da ordem do expor, com implicação nos parâmetros da ação de linguagem - por exemplo, "je vous présenterai" ${ }^{10}$ ) e o discurso teórico (mundo discursivo da ordem do expor, em relação de autonomia dos parâmetros da ação de linguagem - por exemplo, "En psychologie, on parle de..."; "Les théoriciens du discours affirment que...").

No que diz respeito aos mecanismos de textualização, o gênero se caracteriza por:

- conexão: marcadores de estruturação do discurso (d'abord, après, ensuite, en plus, je vous présenterai); marcadores com a função de ligação (et, ou, mais); conectivos que distinguem as ideias principais das secundárias (surtout);

- coesão nominal: anáforas pronominais (cette étude, cette recherche, cette image, cet auteur, cela/ça);

No que diz respeito aos mecanismos de responsabilização enunciativa, observou-se a predominância da voz do estudante / pesquisador que conduziu o estudo / a pesquisa (on a étudié; on a identifié, on peut voir que, notre question, nos résultats, mon travail...) apresentada na primeira pessoa do plural (nous, on) ou, com menos frequência, na primeira pessoa do singular (ma thèse, mon travail). O uso da primeira pessoa do plural (nous) e do on com valor de nós demonstra a intenção, por parte do apresentador, de incluir a comunidade científica restrita na qual desenvolve a pesquisa, como, por exemplo, orientador e colegas. $\mathrm{Na}$ apresentação do quadro teórico ou dos conceitos, convocam-se vozes de correntes teóricas ou de pesquisadores da área que dão legitimidade à pesquisa ("Selon Clot", "Pour l'ISD"). Também foi possível identificar vozes do senso-comum ou da comunidade não científica na apresentação da problemática ("On croit souvent", "Pour la majorité des personnes"). Com relação às modalizações, encontramos a presença,

10 Os termos em francês foram extraídos de nosso corpus para a constituição do MD.

LOUSADA, E. G., SILVA, E. C., DIAS, A. P. S. 0 ensino da apresentação oral em francês e sua contribuição para o Letramento Acadêmico e para o Plurilinguismo na ciência 
predominantemente, de modalizações lógicas (ordem da verdade, da possibilidade - c'est vrai que), mas, também, de deônticas (ordem da obrigação e/ou necessidade - il faut), pragmáticas (ordem da responsabilidade do agente - nous avons pu constater, nous avons réussi) que variam em função do tom assumido pelo produtor do texto, que pode ser de caráter mais ou menos assertivo, mais ou menos categórico em função do papel que assume na relação com o público.

Considerando que esse gênero se realiza oralmente, é preciso levar em conta os traços relevantes dessa oralidade na construção do texto. Baseando-nos no que observa Zani (2018), uma vez que o texto falado se constrói sob pressões de ordem pragmática, sua sintaxe é sacrificada em função das necessidades da interação, acarretando "falsos começos, truncamentos, correções, hesitações, mas também inserções, repetições, paráfrases” (KOCH, 2012, p. 81), assim, fazem-se necessárias categorias específicas para análise da construção do texto falado. A autora destaca, de um lado, as estratégias de inserção e reformulação (retórica ou saneadora) e, de outro, a compreensão das hesitações através de marcadores conversacionais (linguísticos e não linguísticos; de natureza verbal ou prosódica), os quais podem funcionar como organizadores da interação, articuladores dos textos ou indicadores da força ilocutória. Isso posto, para o MD, foram consideradas as seguintes características do texto oral:

- segmentos de inserção explicativa (c'est pour cela, parce que, comme ça) e ilustrativa (par exemple, prenons un exemple);

- segmentos de reformulações retóricas (autrement dit) ou saneadoras (pardon, je veux dire, c'est-à-dire);

- segmentos fazendo referência à projeção (voici, voilà, là vous voyez ${ }^{11}$ )

O MD que acabamos de apresentar nos permite identificar diferenças e semelhanças entre sua produção em contexto francófono e em contexto brasileiro. De um lado, as semelhanças podem ser notadas no domínio da linguagem formal; na preocupação com os aspectos do oral (entonação, ritmo, voz, interação com

11 Os termos em francês foram extraídos de nosso corpus para a constituição do MD. 
o interlocutor); na organização geral dos tópicos a serem apresentados, os quais seguem uma sequência mais ou menos canônica na esfera acadêmica: introdução (justificativa, objetivos, perguntas de pesquisa etc.), fundamentação teórica, metodologia, resultados, conclusão. De outro, as diferenças se constatam na particularidade da introdução feita em contexto francófono, quando, antes de se apresentar os objetivos, faz-se necessário contextualizar e evidenciar a problemática que dá origem à pesquisa. Outra diferença é a marcação do plano da apresentação no decorrer da apresentação: a organização da fala se dá em partes, e a explicitação dessas partes são características muito presentes nas apresentações orais em mundo francófono. Quando essas diferenças e semelhanças são observadas e trabalhadas de forma explícita no ensino do gênero, tornam seu aprendizado mais palpável e consciente e permitem uma ampliação da reflexão sobre a produção do gênero no contexto de origem.

Apresentado o MD, a próxima seção descreve como o trabalho com o gênero apresentação oral foi realizado no contexto do curso.

\section{c) Etapas do trabalho com o gênero apresentação oral}

O trabalho com o gênero apresentação oral teve início no módulo 4, com uma discussão sobre questões que tinham como objetivo introduzir o assunto falar sobre a pesquisa. Os alunos deveriam dizer em que situações ligadas à vida universitária eles poderiam ter dificuldades de comunicação e quais situações de apresentação da pesquisa eram estressantes para eles. Após compartilhar as respostas com todo o grupo, os alunos assistiram a uma apresentação oral de um concurso chamado "Minha tese em 180 segundos" e tinham como tarefa identificar o objetivo da pesquisa apresentada, para, em um segundo momento, discutir a maneira como o pesquisador se apresenta e quais eram as estratégias utilizadas por ele para apresentar sua pesquisa. Uma vez identificadas as estratégias usadas pelo pesquisador, coube a eles identificar quais lhes pareciam úteis, bem como quais outras estratégias eles conheciam, para, finalmente, fazer uma síntese que reunisse as estratégias que eles consideravam mais eficazes para realizar uma boa apresentação oral. Após compartilharem suas respostas com o grupo, os alunos leram um texto intitulado 
"Como falar em público: dar um curso ou uma conferência" (tradução nossa) ${ }^{12} \mathrm{e}$ discutiram quais dos conselhos presentes no texto lhes pareciam pertinentes.

Após essa introdução ao gênero, os alunos foram expostos, no módulo 5, a diferentes resumos para comunicações orais e deveriam observar quais eram os elementos presentes nos textos, sua organização e o modo como os objetivos foram formulados. Depois de identificar as características desse gênero, os alunos elaboraram um resumo de suas pesquisas visando propor uma apresentação oral em um congresso francófono. Os resumos foram partilhados e discutidos em sala, levando em conta as características pontuadas inicialmente.

Com os resumos prontos, era o momento de pensar na sua própria apresentação oral; para isso eles assistiram a um vídeo de uma comunicação oral de uma estudante de mestrado em um congresso francófono e deveriam observar as partes em que a comunicação estava dividida e o modo como elas estavam organizadas. Munidos dos resumos preparados por eles e das características de uma apresentação oral identificadas a partir do vídeo, os alunos elaboraram um plano para uma apresentação de 5 minutos, todos se apresentaram e receberam comentários e contribuições dos demais colegas. Como tarefa, os alunos organizaram um plano para uma apresentação de 20 minutos, portanto, mais longa. Essa comunicação seria realizada no último dia do curso, no módulo 7 , e os planos foram discutidos em sala por todos. Além do plano, os alunos elaboraram uma ficha de avaliação, que levava em conta as características do gênero apresentação oral. Tal ficha deveria ser utilizada para avaliar cada uma das apresentações no último dia do curso.

Entre o módulo 5 e o módulo 7, em que seriam feitas as apresentações orais, os alunos tiveram atendimentos individuais no Laboratório de Letramento Acadêmico, justamente, com as monitoras do LLAC que também eram professoras do curso, o que os auxiliou sobremaneira na preparação da apresentação oral.

Da forma como foram realizadas, as atividades que apresentamos se constituíram em uma SD, tal como proposta por Dolz, Noverraz e Schneuwly (2004), pois foi solicitada uma primeira apresentação oral da pesquisa, na primeira aula, antes que as atividades fossem aplicadas. Após esse primeiro momento, que pode

12 «Comment parler en public: donner un cours ou une conférence» 
Linha D'Água (Online), São Paulo, v. 33, n. 2, p. 161-188, maio-ago. 2020

ser considerado uma produção inicial, foram propostos três módulos sobre esse mesmo gênero, sendo que, no segundo (módulo 5), foi feita uma produção intermediária (apresentação 2). Finalmente, o último módulo previu a apresentação final das pesquisas (apresentação 3), ou seja, a produção final.

No quadro abaixo, vemos uma síntese dos objetivos dos três módulos do curso que focaram a apresentação oral, com algumas das atividades propostas:

\begin{tabular}{|c|c|c|}
\hline Módulos & Objetivo & Atividades \\
\hline Módulo 4 & $\begin{array}{l}\text { - Refletir sobre o } \\
\text { contexto de produção } \\
\text { das apresentações de } \\
\text { congressos } \\
\text { - Inserir a voz dos autores } \\
\text { no texto escrito e no oral }\end{array}$ & $\begin{array}{l}\text { - Discussão com os pares e com o grupo sobre as } \\
\text { situações em que se fala da pesquisa } \\
\text { - Observação e análise de uma apresentação oral para o } \\
\text { concurso "Minha tese em } 180 \text { segundos" } \\
\text { - Leitura e discussão de um texto sobre o "falar em } \\
\text { público" }\end{array}$ \\
\hline Módulo 5 & $\begin{array}{l}\text { - Refletir sobre a passagem } \\
\text { do resumo à apresentação } \\
\text { oral } \\
\text { - Pensar na estrutura } \\
\text { da apresentação oral e } \\
\text { observar exemplares do } \\
\text { gênero }\end{array}$ & $\begin{array}{l}\text { - Leitura e análise de diversos resumos } \\
\text { - Elaboração do próprio resumo } \\
\text { - Seleção dos conteúdos do resumo a serem } \\
\text { apresentados oralmente } \\
\text { - Observação e análise das características de uma } \\
\text { apresentação oral mais longa } \\
\text { - Apresentação, em } 5 \text { minutos, de sua pesquisa (2) } \\
\text { [filmagem] }\end{array}$ \\
\hline Módulo 7 & $\begin{array}{l}\text { - Preparar a apresentação e } \\
\text { pensar na avaliação }\end{array}$ & $\begin{array}{l}\text { - preparação da apresentação oral } \\
\text { - realização da apresentação oral de } 20 \text { minutos (3) } \\
\text { [filmagem] }\end{array}$ \\
\hline
\end{tabular}

Quadro 3: Conteúdos dos Módulos 4, 5 e 6 do curso - Objetivos e Atividades

Fonte: Elaboração própria

Com relação à coleta de dados, a produção da primeira apresentação (1) pelos alunos se realizou no primeiro dia de aula, de maneira um pouco mais informal, e não foi filmada. A produção da segunda apresentação (2) se deu através da simulação de uma situação de apresentação de pesquisa para os colegas francófonos em 
um seminário de pesquisa, com duração máxima de cinco minutos, e foi filmada. A terceira apresentação (3) foi produzida na situação simulada em um congresso de pesquisas, com duração máxima de vinte minutos, e também foi filmada.

Para realizar a análise das produções alunos, baseamo-nos na observação da mobilização das capacidades de linguagem de acordo com os itens descritos no MD e trabalhados na SD, identificando os aspectos que foram mais ou menos mobilizados. Neste artigo, por questões de espaço, optamos por apresentar a análise comparativa das apresentações 2 e 3, das quais conservamos os filmes. Entretanto, acreditamos que a comparação entre essas duas apresentações é bastante significativa em relação ao que os alunos produziram, no geral, do início ao final do curso.

\section{Resultados das análises}

Antes de passarmos para a apresentação da análise das capacidades de linguagem de forma comparativa entre a apresentação 2 e 3 , vejamos algumas características das duas produções. Como dissemos, a apresentação 2 ocorreu aproximadamente na metade do curso, e observamos que elas eram: muito informais, continham muitas hesitações, os alunos não apresentam o plano da apresentação, e eles não se colocam como doutorandos/pesquisadores brasileiros. No momento da apresentação, recorrem muito à ajuda visual do caderno, para poder acompanhar sua fala. Além disso, observamos que falta domínio do vocabulário específico e das formas de falar de sua pesquisa.

Já na terceira apresentação, observamos que os estudantes começam a ter maior domínio da linguagem formal e agem como pesquisadores que vão apresentar sua pesquisa, dizendo o que farão e o que não poderão fazer naquela apresentação específica. Do ponto de vista cinético, observamos que eles olham mais para o interlocutor, preocupando-se com ele e se apresentando ao público. Contrariamente à apresentação 2 , os estudantes não utilizam o apoio visual do caderno e preparam slides em power-point, o que é esperado em congressos das áreas às quais eles pertencem. Observamos, também, menos hesitações, maior domínio do vocabulário da pesquisa e, ainda, os alunos apresentam o plano da comunicação oral, como viram que ocorre em apresentações orais de pesquisadores francófonos. 
Linha D'Água (Online), São Paulo, v. 33, n. 2, p. 161-188, maio-ago. 2020

As apresentações foram analisadas com base nas capacidades de linguagem, obtendo-se os seguintes resultados na comparação da $2^{\mathrm{a}}$ e da $3^{\mathrm{a}}$ produção:

\begin{tabular}{|c|c|c|}
\hline & 1a apresentação & 3a apresentação \\
\hline $\begin{array}{l}\text { Capacidades } \\
\text { de ação }\end{array}$ & $\begin{array}{l}\text { - } \quad \text { se apresentam de uma maneira mais } \\
\text { informal; } \\
\text { - } \quad \text { não levam em conta o público. }\end{array}$ & $\begin{array}{l}\text { - } \quad \text { se apresentam de maneira formal; } \\
\text { - } \quad \text { levam em conta o público apresentando } \\
\text { explicações de termos que poderiam } \\
\text { causar dificuldade de compreensão para } \\
\text { um público de outras áreas; } \\
\text { - } \quad \text { apresentação formal. }\end{array}$ \\
\hline $\begin{array}{l}\text { Capacidades } \\
\text { discursivas }\end{array}$ & $\begin{array}{l}\text { - há uma organização da fala, no } \\
\text { entanto ela não é explicitada } \\
\text { anteriormente ao público (não há } \\
\text { um plano da apresentação). }\end{array}$ & $\begin{array}{l}\text { - maior organização da fala explicitada } \\
\text { anteriormente ao público através de um } \\
\text { plano da apresentação; } \\
\text { - } \text { maior uso de discurso teórico. }\end{array}$ \\
\hline $\begin{array}{l}\text { Capacidades } \\
\text { linguístico- } \\
\text { discursivas }\end{array}$ & $\begin{array}{l}\text { - } \quad \text { pouco uso de conectivos; } \\
\text { - } \quad \text { poucas variações verbais e formas } \\
\text { de inserção de vozes; } \\
\text { - } \quad \text { utilização de menor quantidade de } \\
\text { estratégias para evitar a repetição. }\end{array}$ & 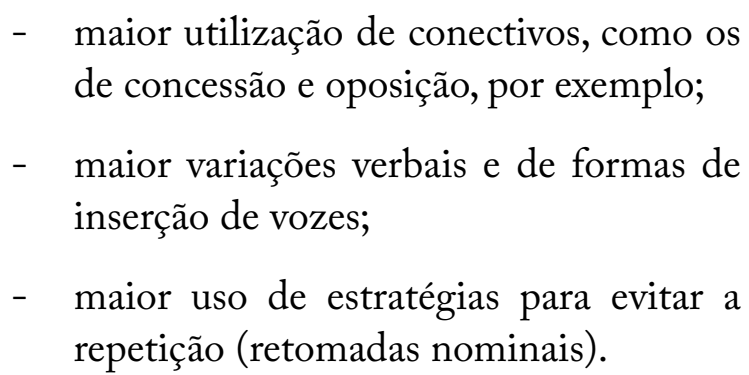 \\
\hline
\end{tabular}

Quadro 4: Síntese das capacidades de linguagem mobilizadas nas produções dos alunos

Fonte: Elaboração própria

Os resultados apontam para um grande desenvolvimento das capacidades de ação, uma vez que os alunos mudaram a maneira de se apresentar: além de seus nomes, informaram a área de suas pesquisas e se eram alunos de mestrado ou doutorado; além disso, o nível de formalidade da comunicação também foi maior, já que eles se comportaram como se estivessem realmente em um congresso. Ademais, passaram a levar o público em conta, por exemplo, ao apresentar explicações sobre temas específicos de sua área que poderiam causar algum tipo de incompreensão.

Constatou-se igualmente um importante desenvolvimento das capacidades discursivas, tendo em vista que os alunos compreenderam a necessidade 
de organizar a fala e de explicitar essa organização; aprenderam a apresentar o plano da apresentação e a situar o momento da fala. A apresentação do plano da apresentação e o fato de ser capaz de situar o momento da fala revelam um uso da linguagem para organizar o pensamento, o que, segundo o que mencionamos em nossa Fundamentação Teórica, pode apontar para um uso da linguagem enquanto instrumento simbólico, na visão vygotskiana (FRIEDRICH, 2012), auxiliando a própria realização do pensamento sobre a pesquisa. Esse exemplo nos mostra, mais uma vez, o quanto, no ser humano, as relações pensamento e linguagem estão sempre imbricadas.

Finalmente, verificou-se um desenvolvimento das capacidades linguísticodiscursivas: os alunos aprenderam a utilizar mais apropriadamente os conectivos de concessão e oposição; houve maior variação de verbos e formas de inserir vozes; também observamos o uso mais variado de estratégias para evitar repetições (pronomes e nominalizações). Observou-se que alguns erros linguísticos em língua francesa persistem, constituindo obstáculos de aprendizagem para estrangeiros/ brasileiros que estão, ao mesmo tempo, aprendendo a fazer uma apresentação da pesquisa e aprendendo a língua em que farão a apresentação.

\section{Considerações finais}

Neste artigo, tivemos como objetivo apresentar os resultados de um curso sobre escrita acadêmica em francês, mostrando o trabalho com o ensino do gênero apresentação oral, com foco na análise do material didático proposto e das produções textuais dos alunos, procurando verificar se houve desenvolvimento das capacidades de linguagem dos alunos. De forma geral, podemos dizer que, diante dos resultados obtidos, o curso foi muito positivo. Os alunos aprenderam vários aspectos da escrita acadêmica e das apresentações orais acadêmicas. Como mostramos em nossas análises, houve um grande desenvolvimento das três capacidades de linguagem em relação ao gênero apresentação oral, ainda que vários dos erros linguísticos dos alunos tenham persistido. Além disso, os alunos se familiarizaram com o gênero apresentação oral em contexto francófono que, como mencionamos, tem diferenças da maneira como o gênero se organiza no contexto brasileiro. 
Embora não tenhamos podido relatar neste artigo, os atendimentos individuais, no âmbito do Laboratório de Letramento Acadêmico, foram cruciais para o trabalho com a apresentação oral, pois permitiram que os alunos tirassem dúvidas específicas. Esse é um ponto que merece ser ressaltado: nesse tipo de curso, os alunos chegam com um nível bastante heterogêneo, e, portanto, é difícil trabalhar com todos os erros linguísticos cometidos por eles, seja porque os erros são muito distintos, seja porque a carga horária do curso, apenas $21 \mathrm{~h}$ presenciais, não permite aprofundamento dos aspectos linguísticos que não estejam diretamente ligados aos gêneros que já estão previstos no curso. Nesse sentido, seria pertinente que houvesse um curso paralelo, focando os aspectos linguísticos, e proposto segundo o nível real dos alunos.

De qualquer forma, é importante ressaltar que os alunos, depois de finalizado o curso, responderam a um questionário, no qual disseram que o curso foi de extrema importância para a aprendizagem dos gêneros acadêmicos e para o aperfeiçoamento de seu nível linguístico em francês. Após o curso, os alunos mantiveram contato com as professoras, sendo que alguns relataram seu desempenho nas atividades de pesquisa no país francófono, revelando-se bastante satisfeitos com o que aprenderam no curso.

Para além da compreensão das diferenças entre o gênero apresentação oral em contexto francófono e brasileiro, fazemos também a hipótese de que o fato de trabalhar com o gênero em francês contribui para o desenvolvimento de capacidades de linguagem que podem ser usadas tanto para outros gêneros que demandem a mobilização de capacidades de linguagem semelhantes, como vimos em Dias (2017), quanto para a transferência das capacidades para a produção de apresentações orais em outras línguas (de ação e discursivas, sobretudo), como o português. Nessa perspectiva, o curso pode ter ajudado os alunos a se familiarizarem e adentrarem mais na esfera acadêmica, auxiliando-os em sua formação como pesquisadores. Além disso, ao discorrerem sobre suas pesquisas em língua estrangeira, os alunos realizaram o que Gajo (2013) descreve como re-mediação, contribuindo para o processo de construção de saberes. Nesse sentido, a partir dos relatos positivos dos alunos, acreditamos que a re-mediação possa ter proporcionado igualmente um novo olhar sobre suas pesquisas, tal como Gajo (2013) aponta. 
Assim, o curso se revelou, após três edições, um fator crucial de investimento em uma política linguística plurilíngue, que considera que o francês também é uma língua importante na divulgação da ciência. Com efeito, muitos dos alunos da Universidade de São Paulo fazem seus estudos, seja em nível de doutorado (CAPES-PDSE) ou de graduação, por meio de diferentes bolsas e convênios com países francófonos ${ }^{13}$. Portanto, esse curso tem um importante papel nas ações da Universidade e, em especial, da Pró-Reitoria de Pós-Graduação na preparação de pós-graduandos para a divulgação de suas pesquisas em língua francesa, e contribuindo, dessa forma, para a internacionalização da Universidade de São Paulo.

\section{Referências}

BAZERMAN, C.; BONINI, A.; FIGUEIREDO, D. (Orgs.) Genre in a changing world. Fort Collins, Colorado: The WAC Clearinghouse and Parlor Press, 2009.

BLANCHET, P. De l'importance du plurilinguisme dans l'élaboration et la diffusion de recherches innovantes en sciences humaines et sociales. In: FRATH, P.; HERRERAS, J.C. (orgs.) Plurilinguisme et créativité scientifique. Vincennes: Observatoire Européen du Plurilinguisme, 2017, p. 103-113.

BLANCHET, P.; CHARDENET, P. Les orientations et les pratiques éducatives comme politiques linguistiques effectives: propositions pour une analyse glottopolitique des transpositions didactiques de la pluralité linguistique dans les universités d'Amérique du Sud. In: CUNHA, J. C.; LOUSADA, E. G. (Org.). Pluralidade linguístico-cultural em universidades sul-americanas: práticas de ensino e políticas. 1. ed. São Paulo: Pontes Editora, 2016. p. 167-202.

BRONCKART, J.-P. Atividade de linguagem, textos e discursos. Por um interacionismo sociodiscursivo. São Paulo: Educ. 1999.

13 Em consulta ao site da Agência USP de Cooperação Acadêmica Nacional e Internacional em fevereiro de 2020, verificaram-se 253 Convênios Acadêmicos de Cooperação Internacional e de Dupla-Titulação vigentes firmados com Instituições de Ensino Superior de países francófonos, os quais representam $18 \%$ de todos os convênios da USP e de $27 \%$ dos Convênios de Dupla Titulação / Coorientação de Tese da USP.

LOUSADA, E. G., SILVA, E. C., DIAS, A. P. S. 0 ensino da apresentacạ̃o oral em francês e sua contribuição para o Letramento Acadêmico e para o Plurilinguismo na ciência 
Linha D'Água (Online), São Paulo, v. 33, n. 2, p. 161-188, maio-ago. 2020

Atividade de Linguagem, Discurso e Desenvolvimento Humano. Campinas: Mercado de Letras, 2006.

Gêneros de textos, tipos de discurso e sequências. Por uma renovação do ensino da produção escrita. Letras, Santa Maria, v. 20, n. 40, p. 163-176, 2010.

Développement du langage et développement psychologique. L'approche de l'interactionnisme socio-discursif. Veredas, v. 21, n. 3, p. 30-46, 2017.

BUENO, L; ZANI, J. B. O ensino de um gênero textual oral e a elaboração de uma ferramenta didática. Entretextos, v. 19, n. 1, p. 43, 2019.

CERQUIGLINI, B. Le Plurilinguisme en faveur de la Science. Synergies Europe, n. 8, p. 11-17, 2013.

DELCAMBRE, I.; LAHANIER-REUTER, D. Les littéracies universitaires : Influence des disciplines et du niveau d'étude dans les pratiques de l'écrit, Diptyque n. 18, L'appropriation des discours universitaires. Namur : Presses Universitaires de Namur, 2010, p. 11-42.

DE PIETRO, J.-F.; ERARD, S.; KANEMAN-POUGATCH, M. Un modèle didactique du "débat": de l'objet social à la pratique scolaire. Enjeux - Revue de didactique du français, v. 39/40, p. 100-129, 1996.

DE PIETRO, J.-F.; SCHNEUWLY, B. Le modèle didactique du genre: un concept de l'ingénierie didactique. Les cabiers THÉODILE, n. 3, janvier 2003, p. 27-52.

DIAS, A. P. S. O desenvolvimento da produção escrita de alunos de francês a partir do trabalho com gêneros acadêmicos résumé e note de lecture. Dissertação (Mestrado em Língua e Literatura Francesa) - Faculdade de Filosofia, Letras e Ciências Humanas, Universidade de São Paulo, São Paulo, 2017.

DOLZ, J.; NOVERRAZ, M.; SCHNEUWLY, B. Sequências Didáticas para o oral e a escrita: apresentação de um procedimento. In: SCHNEUWLY, B.; DOLZ, J. Gêneros orais e escritos na escola. Campinas: Mercado de Letras, 2004. p. 95-128

DOLZ, J.; PASQUIER, A.; BRONCKART, J.-P. L'acquisition des discours: émergence d'une compétence ou apprentissage de capacités langagières ? Études de Linguistique Appliquée, n. 92, p. 23-37, 1993.

LOUSADA, E. G., SILVA, E. C., DIAS, A. P. S. 0 ensino da apresentação oral em francês e sua contribuição para o Letramento Acadêmico e para o Plurilinguismo na ciência 
Linha D'Água (Online), São Paulo, v. 33, n. 2, p. 161-188, maio-ago. 2020

DOLZ, J.; SCHNEUWLY, B. Pour un enseignement de l'oral: Initiation aux genres formels à l'école. 4 ed. Issy-les-Moulineaux: ESF Éditeur, 2009.

FERREIRA, M. M.; LOUSADA, E. G. Ações do laboratório de letramento acadêmico da universidade de São Paulo: Promovendo a escrita acadêmica na graduação e na pós-graduação. Ilha do Desterro, v. 69, n. 3, p. 125-138, 2016.

FRIEDRICH, J. Lev Vigotski-Mediação, Aprendizagem e Desenvolvimento. Uma leitura filosófica e epistemológica. Campinas: Mercado de Letras, 2012.

GAJO, L. Le plurilinguisme dans et pour la science: enjeux d'une politique linguistique à l'université. Synergies Europe, n. 8, p. 97-109, 2013.

KOCH, I. G. V. O texto e a construção dos sentidos. 10 ed. São Paulo: Contexto, 2012.

LOUSADA, E. G.; DEZUTTER, O. La rédaction de genres universitaires: pratiques et points de vue d'étudiants universitaires au Brésil et au Québec. Le français à l'université, 21º ano, n.01, 2016.

LOUSADA, E. G.; DEZUTTER, O.; ZAVAGLIA, A. Se former à la rédaction de la note de lecture en contexte universitaire. Scripta, v. 21, n. 43, p. 65, 2017.

LOUSADA, E. G.; GUIMARÃES-SANTOS, L. O ensino da escrita acadêmica em francês como língua estrangeira. In: FERREIRA, M. M.; STELLA, V. C. R. (Orgs.). Redação Acadêmica. Múltiplos olhares para o ensino da escrita em português e em linguas estrangeiras. 1. ed. São Paulo: FFLCH/Humanitas, 2018, p. 247-272.

LOUSADA, E. G.; ROCHA, S. M.; GUIMARÃES-SANTOS, L. Gêneros orais, projetos didáticos de gêneros e mobilidade estudantil: perspectivas para ensinar a agir em francês como língua estrangeira. In: BUENO, L.; COSTA-HÜBES, T.C. (Org.). Gêneros orais no ensino. Campinas, SP: Mercado de Letras. São Paulo: Mercado de Letras, 2015, p. 321-355.

RAMOS, M. Y.Internacionalização da pós-graduação no Brasil: lógica e mecanismos. Educação e Pesquisa, 2018, vol.44, e161579. https://doi.org/10.1590/s1517-9702201706161579

SCHNEUWLY, B.; DOLZ, J. Gêneros orais e escritos na escola. Tradução e organização de Roxane Rojo e Glaís Cordeiro. Campinas: Mercado de Letras, 2004.

LOUSADA, E. G., SILVA, E. C., DIAS, A. P. S. 0 ensino da apresentação oral em francês e sua contribuição para o Letramento Acadêmico e para o Plurilinguismo na ciência 
Linha D'Água (Online), São Paulo, v. 33, n. 2, p. 161-188, maio-ago. 2020

SILVA, E. C.; LOUSADA, E. G. O plano de estudos: um gênero textual acadêmico para pleitear intercâmbio. Horizontes, v. 32, n. 2, p. 73-87, jan./jun.2014 https://doi.org/10.24933/horizontes.v32i1.91

SILVA, E. C.; MENEZES, M. C.; LOUSADA, E. G. Um estudo sobre as políticas linguísticas que regem a pluralidade linguística e cultural em dois contextos de ensino de francês na Universidade de São Paulo. In: CUNHA, J. C.; LOUSADA, E. G. (Orgs.). Pluralidade linguístico-cultural em universidades sul-americanas: práticas de ensino e políticas. 1. ed. São Paulo: Pontes Editora, 2016. p. 167-202.

SWALES, J. M. Occluded genres in the Academy: The case of the Submission Letter. In: VENTOLA, E.; MAURANEN, A. Academic Writing: Intercultural and Textual Studies. Amsterdam/ Philadelphia: John Benjamins Publishing Company, 1996, p. 45-58.

VYGOTSKI, L. S. Pensée et langage. Trad. Françoise Sève. Paris: La Dispute, 1934/1997.

ZANI, J. B. A comunicação oral em eventos cientificos: uma proposta de modelização para elaboração de sequências didáticas. Tese de doutorado. Universidade São Francisco, Itatiba, 2018.

Recebido: 15/02/2020.

Aprovado: 8/05/2020.

LOUSADA, E. G., SILVA, E. C., DIAS, A. P. S. 0 ensino da apresentação oral em francês e sua contribuição para o Letramento Acadêmico e para o Plurilinguismo na ciência 